\title{
Maíz nixtamalizado suplementado con un concentrado de proteínas de sardina para mejorar el valor biológico de las tortillas
}

\author{
Mardia López-Alarcón, ${ }^{1}$ Irene Montalvo-Velarde, ${ }^{2}$ Lilia Bernal-Gracida ${ }^{3}$ y \\ María de Lourdes Barbosa-Cortés ${ }^{1}$ \\ 'Instituto Mexicano del Seguro Social, Centro Médico Nacional Siglo XXI, Hospital de Pediatría; 'Universidad La Salle, Facultad de Química; \\ ${ }^{3}$ Universidad Nacional Autónoma de México, Facultad de Ciencias Químicas, Departamento de Bioquímica. Ciudad de México, México
}

\begin{abstract}
Resumen
Introducción: La mayor parte de la población rural en México adquiere casi la mitad de su energía de la tortilla de maíz y sus fuentes de proteína son principalmente de origen vegetal. Objetivo: Obtener un concentrado de proteína de sardina para adicionar harina de maíz e identificar la concentración que proporcione la mejor calidad biológica de las tortillas sin modificar sus características físicas y sensoriales. Método: Obtención de un concentrado de proteína de sardina y elaboración de tortillas con harina de maíz suplementada con diferentes concentraciones de proteína. Las características físicas y sensoriales de las tortillas fueron evaluadas por panelistas no entrenados. La calidad biológica de las tortillas se analizó en un modelo murino (crecimiento y la relación de eficiencia de proteína, PER). Para el análisis se utilizó estadística paramétrica. Resultados: Se obtuvo un concentrado de proteína con $70.48 \mathrm{~g} / 100 \mathrm{~g}$. La suavidad, inflado, doblado y calidad de las tortillas preparadas con las mezclas con $0.63-3.75 \%$ de proteínas de sardina fueron comparables con los de las tortillas elaboradas con harina no adicionada. El crecimiento de las ratas alimentadas con tortillas adicionadas fue mayor que el de las alimentadas con harina no adicionada; la diferencia fue significativa a partir de la concentración de $3.75 \%(p<0.05)$. El PER de las tortillas con $3.75 \%$ de proteínas de sardina fue de 2.41, comparable al de la proteína de referencia (caseína). Conclusión: La harina de maíz adicionada con proteínas de sardina en una proporción de 96.25:3.75 \% mejora el valor biológico de las tortillas sin alterar sus características físicas y sensoriales.
\end{abstract}

PALABRAS CLAVE: Maíz nixtamalizado. Sardina. Concentrado de proteína. Tortillas de maíz.

\begin{abstract}
Introduction: Most part of the rural population in Mexico obtains almost half its energy from corn tortilla, and its sources of protein are mainly of vegetal origin. Objective: To obtain a concentrate of sardine protein (SP) to supplement corn flour, and to identify which concentration provides corn tortillas with a better biological value, without modifying its physical and sensorial characteristics. Method: Obtainment of the SP concentrate, preparation of tortillas with corn flour and different SP concentrations, assessment of tortillas physical and sensorial characteristics by untrained panelists, assessment of biological quality in a murine model (growth and protein efficiency ratio [PER]). Parametric statistics was used. Results: A protein concentrate of $70.48 \mathrm{~g} / 100 \mathrm{~g}$ was obtained. Smoothness, blistering, foldability and quality of the tortillas prepared with mixtures containing $0.63-3.75 \%$ of SP were comparable to those of tortillas prepared with non-supplemented flour. The growth of rats fed supplemented tortillas was superior; the difference was significant with $\geq 3.75 \%$ concentrations $(p<0.05)$. The PER of tortillas with $3.75 \%$ of SP was 2.41, which was comparable to that of the reference protein (casein). Conclusion: SP-supplemented corn flour at a 96.25:3.75\% ratio improves the biological value of tortillas without modifying their physical and sensorial characteristics.
\end{abstract}

KEY WORDS: Nixtamalized maize. Sardine. Protein concentrate. Corn tortillas.

Correspondencia:

Mardia López-Alarcón

E-mail: marsau2@ prodigy.net.mx
Fecha de recepción: 17-03-2017

Fecha de aceptación: 09-11-2017

DOI://dx.doi.org/10.24875/GMM.17003373
Gac Med Mex. 2018;154:327-334

Disponible en PubMed

www.gacetamedicademexico.com 


\section{Introducción}

Aun cuando el sobrepeso y la obesidad son problemas prioritarios de salud en México, las Encuestas Nacionales de Nutrición en México muestran que la desnutrición infantil sigue siendo un problema importante, sobre todo en las áreas rurales. ${ }^{1-4}$ Por ejemplo, el análisis de las tasas de desmedro a nivel nacional muestra una tendencia importante a la baja, pero en las zonas rurales la prevalencia sigue siendo alta ya que se mantiene por arriba de $20 \%{ }^{4}$ De hecho, las regiones rurales del sur del país mantienen una prevalencia de talla baja 13.9 puntos porcentuales superiores al promedio nacional (27.5 versus $13.6 \%$ ). ${ }^{4} \mathrm{En}$ cuanto a la dieta, la Encuesta Nacional de Nutrición más reciente reporta que si bien en el país existe un exceso en el consumo de energía derivado de los alimentos endulzados lácteos y no lácteos, menos de $50 \%$ de la población rural consume las recomendaciones de alimentos que proporcionan proteínas de calidad como huevo, carne no procesada y lácteos y solo alrededor de $60 \%$ consume las recomendaciones de energía y con un alto contenido de fibra. Estas deficiencias dietarias son aún más grave en los niños escolares que en los adolescentes. ${ }^{5}$

La principal influencia nutricia sobre el crecimiento en los países en desarrollo es el consumo de proteínas y energía. ${ }^{6}$ Además, los requerimientos de proteína aumentan a medida que no se cumple con los requerimientos de energía. ${ }^{7,8}$ Por otra parte, es frecuente que en los países en desarrollo, las fuentes principales de proteína sean los vegetales y cereales, los cuales proporcionan proteínas de bajo valor biológico. ${ }^{8}$ En México, particularmente en las zonas rurales, la mayor parte de la población adquiere por lo menos la mitad de su energía de la tortilla de maíz, y las fuentes de proteína son principalmente de origen vegetal, lo que la hace de baja calidad. ${ }^{9}$ Es importante tomar en cuenta que la proteína del maíz tiene bajas concentraciones de lisina y triptófano, además de que está desequilibrada en la proporción de leucina e isoleucina, factores que interfieren con el crecimiento lineal.10,11 Analizando esto en conjunto, es probable que en las poblaciones de los países en desarrollo, la utilización de la proteína de la dieta sea ineficiente debido al déficit de energía y, aunque el consumo de proteína sea adecuado, la proteína consumida es de bajo valor biológico y en gran parte limitante del crecimiento al provenir casi en su totalidad del maíz.
Estudios previos muy antiguos realizados en niños, ${ }^{12,13}$ adultos $^{14}$ y animales de experimentación ${ }^{15}$ mostraron que el valor nutritivo del maíz nixtamalizado puede mejorarse agregando simultáneamente los tres aminoácidos limitantes: lisina, triptófano e isoleucina, que por su alto costo resulta poco factible a nivel poblacional. También se ha demostrado en modelos animales, la mejoría en la calidad de la tortilla de maíz cuando se suplementa con harina de leguminosas como frijol, soya, garbanzo, habas, y lentejas, pero su utilización en humanos ha sido insuficiente para mejorar el estado nutricio de la población. ${ }^{16,17}$ Un estudio realizado en México en humanos, en el que se elaboraron tortillas con una mezcla de harina de maíz y harina de soya reportó mejoría en el valor biológico de las tortillas, pero no se demostró ningún efecto en el estado nutricio de los niños. ${ }^{18}$

La suplementación con extracto de proteína de alto valor biológico, como la obtenida de fuentes animales, para mejorar la calidad de la harina de maíz ya se ha intentado. ${ }^{19-21}$ La suplementación con harina de pescado se ha efectuado con éxito para alimentación animal, pero su uso en humanos no ha sido aceptado, principalmente porque se ha empleado pescado molido (y no el extracto de proteína), por lo que el olor es muy fuerte y las características de las tortillas no son aceptables para el consumo humano. ${ }^{20,21}$ Por ejemplo, en 1957 se reportó que la relación de eficiencia de proteína (PER, por sus siglas en inglés) del maíz amarillo entero mejoró de 0.61 a 1.34 , y el crecimiento de las ratas aumentó de 21.5 a $71.1 \mathrm{~g}$, cuando se agregó una mezcla de pescados molidos para obtener una dieta en cantidades comparables de proteína. ${ }^{20}$ En humanos, un estudio realizado con dietas complementarias para lactantes a base de arroz o maíz, suplementadas con diferentes fuentes de proteína como frijol, sardina, o ambas, demostró que las puntuaciones de aminoácidos, digestibilidad y tasa de eficiencia fueron mejores en la dieta con las mezclas de sardina. ${ }^{21}$ Es importante tomar en cuenta que en ambos estudios, ${ }^{20,21}$ la suplementación se realizó con mezclas de harina de pescado o el pescado completo y en el estudio en humanos no se analizó el efecto en el crecimiento.

De esta manera, la evidencia sugiere que un enfoque adecuado para mejorar la calidad alimentaria del maíz es la suplementación con proteína de alto valor biológico y la del pescado parece ser una buena opción. En México, la sardina es barata, abundante, y contiene proteína de alta calidad, ${ }^{22}$ por lo que sería una buena alternativa. Si bien idealmente la incorporación 
de la sardina a la dieta sería más adecuada, factores culturales y económicos han impedido que este alimento sea agregado a la dieta del mexicano, por lo que resulta apropiado evaluar la adición de un concentrado de proteína de sardina a la harina de maíz para, eventualmente, mejorar el crecimiento de los niños.

No obstante, es indispensable evaluar si la incorporación del concentrado de proteína a la harina de maíz no modifica las características físicas y sensoriales de la tortilla, de tal manera que esta sea aceptada para su uso en humanos.

El objetivo de este estudio se enfocó en obtener un concentrado de proteína de sardina (PS) para adicionar a la harina de maíz en diferentes proporciones e identificar la mezcla que proporcione las tortillas con características aceptables para el consumo humano. Además, evaluar en un modelo animal el valor biológico de las tortillas elaboradas con las mezclas adicionadas analizando el PER de las tortillas y el crecimiento de las ratas.

\section{Método}

Se realizaron diversos experimentos para obtener un extracto de proteína de sardina (PS). Se elaboraron tortillas con mezclas de harina de maíz y diferentes concentraciones de PS y se evaluaron las características físicas y sensoriales de las tortillas por un grupo de panelistas no entrenados. Posteriormente, en un modelo animal, se analizó la calidad biológica de las tortillas evaluando las curvas de crecimiento de las ratas y la PER.

Se utilizaron sardinas congeladas (Sardina pilchardus) obtenidas de un mercado local y almacenadas a $-80^{\circ} \mathrm{C}$ hasta ser utilizadas. Una vez descongeladas se eliminaron las cabezas y los intestinos de los pescados, y la carne y los huesos se molieron con un molino doméstico (KitchenAid, Hobart). La mezcla obtenida se pasó por un cedazo con orificios de $6 \mathrm{~mm}$ y luego por otro de $4 \mathrm{~mm}$ de diámetro. El material obtenido se combinó con agua en una proporción 1:4 (w/v) y se licuó para obtener una mezcla homogénea. Todo este proceso se llevó a cabo en la Facultad de Ciencias Químicas, en el Laboratorio de Bioquímica, de la Universidad Nacional Autónoma de México.

El compuesto acuoso obtenido se ajustó a un $\mathrm{pH}$ alcalino (12.0) usando $\mathrm{NaOH} 2 \mathrm{~N}$. La mezcla estabilizada se centrifugó a $8000 \mathrm{~g}$ durante 20 minutos a $4^{\circ} \mathrm{C}$ para separar las proteínas solubles. Los lípidos neutros se mantuvieron en la parte superior y el material sólido, principalmente tejido conectivo y hueso, se fue
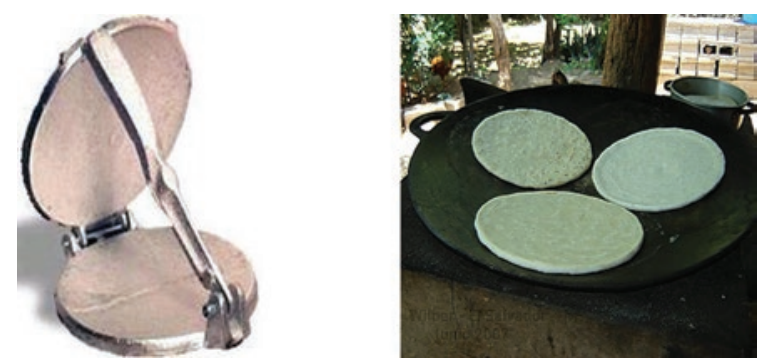

Figura 1. Máquina y comal utilizados para la elaboración de las tortillas.

al fondo. De esta manera se pudo obtener la parte media del mezclado que contenía las proteínas solubilizadas. El pH se ajustó a 5.5 para favorecer la precipitación de las proteínas usando $\mathrm{HCL} 2 \mathrm{~N}$ y finalmente se recuperó la proteína después de una centrifugación a $8000 \mathrm{~g}$ durante 20 minutos a $4^{\circ} \mathrm{C}$ y secado con atomizador (temperatura de entrada de aire a $40^{\circ} \mathrm{C}$ y salida de aire a $65^{\circ} \mathrm{C}$, a una tasa de $30 \mathrm{~mL}$ minuto-1). Se determinó el contenido de la proteína por método de Bradford (1976) y se calculó la concentración usando albúmina de suero bovino como estándar.

Para elaborar las tortillas se utilizó harina de maíz nixtamalizada y se prepararon con harina de maíz no adicionada y con harina de maíz adicionada con diferentes concentraciones de PS. De esta manera se obtuvieron mezclas de masa con las siguientes proporciones de harina de maíz: PS, 92.5:7.5, 95.0:5.0, $96.25: 3.75,97.5: 2.5$, $98.75: 1.25$ y 99.37:0.63. Las tortillas se elaboraron con una máquina convencional y se cocieron colocándolas en un comal por espacio de dos minutos, un minuto por cada lado aproximadamente (Figura 1).

Para evaluar las características físicas y sensoriales de las tortillas se invitó a 20 panelistas no entrenados y no alérgicos al pescado, y se utilizaron escalas subjetivas de calificación. Se evaluaron las tortillas recién hechas tomando como referencia las elaboradas con harina de maíz sin adicionar.

Se calificó sabor, color, olor, suavidad (haciendo presión con las yemas de los dedos sobre la superficie de la tortilla y observando la resistencia a dicha presión) y tersura (falta de aspereza en la superficie de la tortilla), así como las pruebas de inflado (formación de ampollas en la última fase de la cocción) y doblado (enrollar la tortilla sobre sí misma y observar si la parte externa del taco presenta grietas) (Tabla 1). Al final se evaluó la calidad total preguntando si la tortilla era no aceptable, medianamente aceptable o aceptable. 
Tabla 1. Escala para la evaluación sensorial de la tortilla de harina de maíz adicionada con proteína de sardina

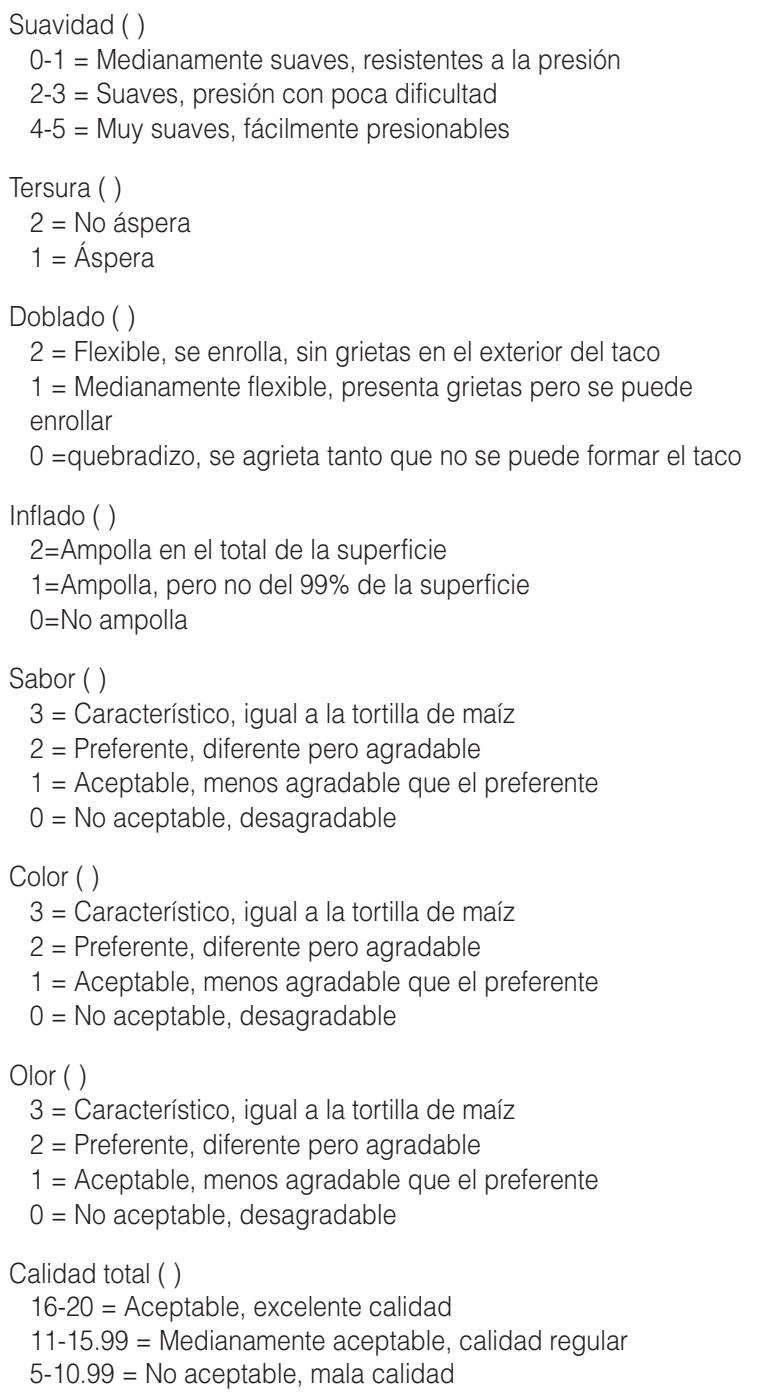

Para las pruebas biológicas se consideraron solamente las dietas de mediana y excelente aceptación.

Para la evaluación de las características químicas de las tortillas primero se determinó el contenido de humedad de acuerdo con la Association of Analytical Communities (AOAC). El contenido de humedad se determinó secando las muestras a $105^{\circ} \mathrm{C}$ en un horno convencional por tres horas y calculando el porcentaje de la diferencia de peso entre la muestra húmeda y la muestra seca. ${ }^{23}$ Posteriormente se secaron a $60^{\circ} \mathrm{C}$, se molieron en un molino para granos y la harina se guardó en frascos de vidrio cerrados herméticamente y etiquetados, en un lugar fresco, para el análisis químico.

El contenido de proteína se analizó por Kjeldahl, el de cenizas por incineración en mufla, la grasa cruda por extracción con solventes (Soxhlet), la fibra cruda
Tabla 2. Dieta base para las pruebas biológicas propuesta por la AOAC*

\begin{tabular}{lc}
\hline Ingrediente & g/100 $\mathbf{g}$ de dieta \\
\hline Proteína & 10 \\
Aceite vegetal & 8 \\
Sales minerales & 5 \\
Mezcla de vitaminas & 1 \\
Agua & 5 \\
Celulosa & 1 \\
Carbohidratos: sacarosa 0 & 70 \\
dextrina & \\
\hline${ }^{*}$ Energía 392 kcal/100 g. Referencia 23 &
\end{tabular}

por hidrólisis ácida y alcalina, y el contenido de carbohidratos totales por diferencia en porcentaje de las determinaciones anteriores. El contenido de energía se calculó a partir de los valores de referencia (4 kcal/g de proteína, $9 \mathrm{kcal} / \mathrm{g}$ de grasa y $4 \mathrm{kcal} / \mathrm{g}$ de carbohidratos).

\section{Pruebas biológicas}

Se determinó el PER de la harina de maíz no adicionada y de las mezclas seleccionadas en las pruebas de evaluación sensorial, usando como comparación una dieta de caseína considerada como la referencia de la calidad de proteína.

Se utilizaron ratas Sprague-Dowley recién destetadas (21 a 23 días de nacidas), agrupadas en lotes de seis animales por cada dieta evaluada. Los animales se colocaron en jaulas individuales y se alimentaron con las dietas problema y controles durante 21 días. Durante este tiempo se les abasteció diariamente con agua y alimento a libertad y se midió el peso y el alimento ingerido cada cinco días para calcular el PER, que se calculó con la siguiente fórmula:

$P E R$ = ganancia de peso (g)/consumo de proteína (g)

Para la elaboración de las dietas isoproteicas e isoenergéticas se tomó como base la fórmula propuesta por la AOAC (Tabla 2).

\section{Análisis estadístico}

Para el análisis estadístico se utilizó el programa estadístico Minitab versión 17, Anova de una vía para comparar el PER entre las diferentes dietas y de dos factores para evaluar el crecimiento en el tiempo de los diferentes grupos. Para la comparación con la dieta control (harina de maíz no adicionada) se usó 


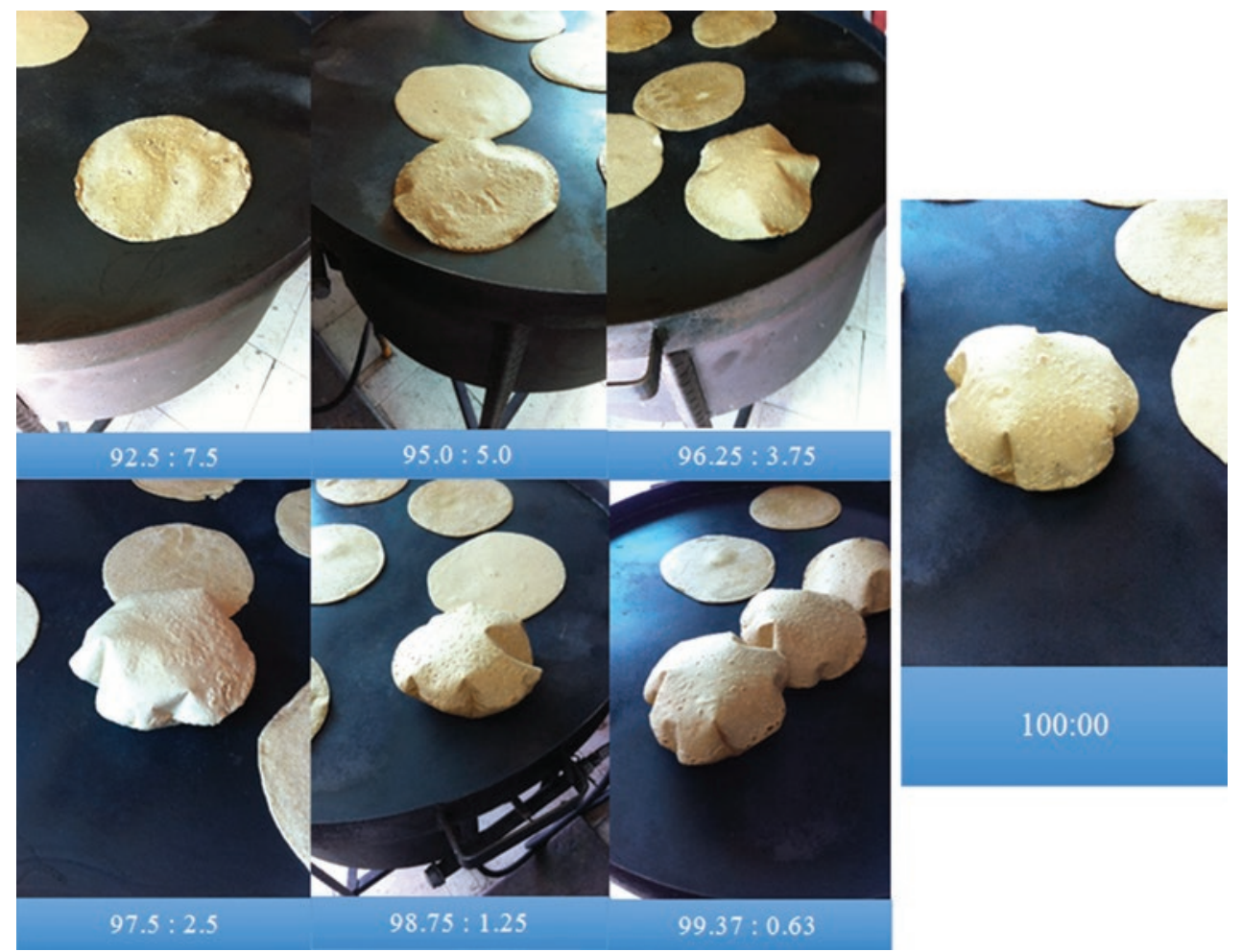

Figura 2. Comparación del inflado de las tortillas elaboradas con las diferentes mezclas de harina de maíz y proteína de sardina (harina de maíz: PS), con las tortillas elaboradas con harina no adicionada.

posprueba de Dunnet y para la comparación entre todas las dietas la prueba de Bonferroni para comparaciones simultáneas.

\section{Resultados}

En la fase experimental para obtener el concentrado de proteína se logró obtener un concentrado con un nivel de $70.48 \mathrm{~g}$ de proteína en $100 \mathrm{~g}$ de producto (Tabla 3) Posteriormente se prepararon las tortillas con las concentraciones propuestas, con las que se observó que desde la mezcla de 96.25:3.75 se inflaban y doblaban en forma comparable con las tortillas preparadas con la harina de maíz no adicionada (Figura 2) El análisis de las pruebas sensoriales mostró que la suavidad, inflado y doblado de las tortillas preparadas con las concentraciones más bajas de PS ( 3.75 a $0.63 \%$ ) eran comparables con los de las tortillas elaboradas con harina de maíz no adicionada. Como consecuencia, la calidad total de estas tortillas se calificó por lo menos como regular. Aunque el olor a sardina era perceptible en la concentración de $3.75 \%$ de PS, los panelistas consideraron que no era desagradable (Tabla 5)

La composición química proximal se determinó en las tortillas elaboradas con harina de maíz no
Tabla 3. Análisis químico proximal de las materias primas para la elaboración de tortillas suplementadas

\begin{tabular}{lcc}
\hline Determinación & Extracto de proteína & Harina de maíz \\
\hline Humedad & 9.42 & 52.77 \\
Proteína & 70.48 & 4.12 \\
Cenizas & 2.35 & 0.83 \\
Grasa cruda & 7.16 & 2.08 \\
Fibra cruda & 0.0 & 1.74 \\
Carbohidratos & 10.59 & 38.46 \\
Kilocalorías & 388.72 & 189.0 \\
\hline
\end{tabular}

adicionada y en las elaboradas con harina de maíz adicionada con diferentes concentraciones de PS; se observó que la adición de proteína fue aparente desde la dosis más baja utilizada (0.63\%) (Tabla 4).

En relación con las pruebas biológicas, las ratas que recibieron caseína o tortillas adicionadas con PS desde 3.75 a $7.5 \%$ crecieron más que las alimentadas con tortillas no adicionadas. Los grupos de animales que recibieron concentraciones más bajas de proteína también crecieron mejor que las de tortilla no adicionada, aunque no alcanzaron significación estadística (Figura 3). 
Tabla 4. Análisis químico proximal de las tortillas elaboradas con diferentes mezclas de harina de maíz y proteína de sardina*

\begin{tabular}{|c|c|c|c|c|c|c|c|}
\hline Parámetro & $92.5: 7.5$ & $95.0: 5.0$ & $96.25: 3.75$ & $97.5: 2.5$ & $98.75: 1.25$ & 99.37:0.63 & 100 \\
\hline \multicolumn{8}{|c|}{ g/100 g, base húmeda } \\
\hline Humedad & 46.38 & 42.10 & 45.44 & 44.29 & 46.02 & 48.09 & 46.89 \\
\hline Proteínas & 10.41 & 9.09 & 7.79 & 6.85 & 5.29 & 5.16 & 4.46 \\
\hline Cenizas & 1.25 & 1.32 & 1.19 & 1.20 & 1.07 & 1.06 & 1.04 \\
\hline Grasa cruda & 1.38 & 1.26 & 1.27 & 1.17 & 1.17 & 0.94 & 1.14 \\
\hline Fibra cruda & 1.15 & 1.79 & 2.05 & 1.75 & 2.02 & 2.11 & 1.96 \\
\hline Carbohidratos & 39.43 & 44.44 & 42.26 & 44.74 & 44.43 & 42.64 & 44.51 \\
\hline Kcal & 211.8 & 225.5 & 211.6 & 216.9 & 209.4 & 199.7 & 206.1 \\
\hline \multicolumn{8}{|c|}{ g/100 g, base seca } \\
\hline Proteínas & 19.42 & 15.70 & 14.28 & 12.29 & 9.80 & 9.95 & 8.40 \\
\hline Cenizas & 2.34 & 2.28 & 2.19 & 2.16 & 1.99 & 2.05 & 1.96 \\
\hline Grasa cruda & 2.58 & 2.18 & 2.32 & 2.11 & 2.17 & 1.82 & 2.14 \\
\hline Fibra cruda & 2.14 & 3.10 & 3.76 & 3.15 & 3.74 & 4.06 & 3.70 \\
\hline Carbohidratos & 73.52 & 76.74 & 77.45 & 80.29 & 82.30 & 82.12 & 83.80 \\
\hline Kcal & 211.8 & 225.5 & 211.6 & 216.9 & 209.4 & 199.7 & 206.1 \\
\hline
\end{tabular}

*La relación corresponde a la proporción harina de maíz:proteína de sardina

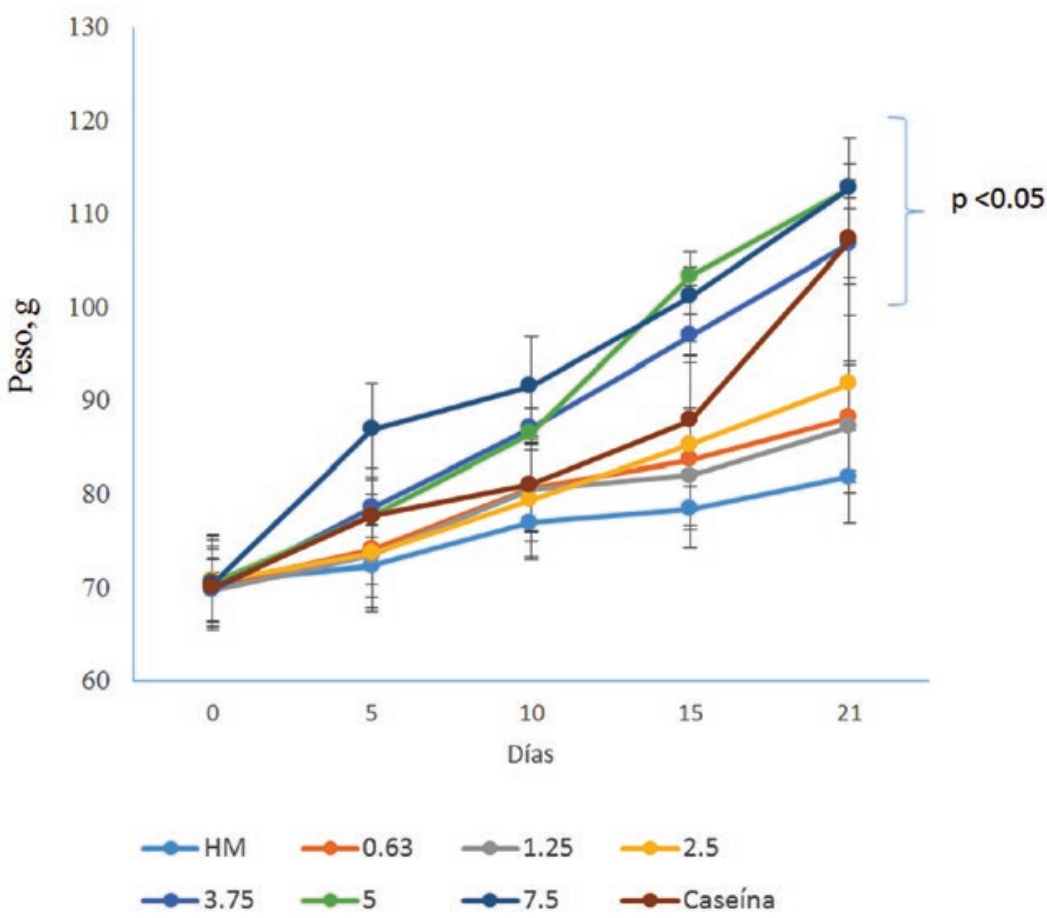

Figura 3. Curvas de crecimiento de las ratas alimentadas con tortillas elaboradas con harina de maíz no adicionada o adicionada con diferentes concentraciones de proteína de sardina durante los 21 días de experimentación. Se formaron ocho grupos de seis ratas alimentadas con harina de maíz no adicionada (HM), con caseína o con las diferentes concentraciones de proteína de sardina (Anova de dos vías).

Dado que las tortillas elaboradas con las mezclas con alta concentración de PS resultaron sensorialmente inadecuadas, el PER se realizó solamente con las mezclas que obtuvieron calificación regular y excelente. La Tabla 5 muestra que el PER con la mezcla 96.25:3.75 fue similar al de caseína, lo que coincidió 
Tabla 5. Evaluación sensorial de las tortillas elaboradas con las diferentes proporciones de harina de maíz: proteína de sardina

\begin{tabular}{|c|c|c|c|c|c|c|c|}
\hline Parámetro & $92.5: 7.5$ & $95: 5$ & $96.25: 3.75$ & $97.5: 2.5$ & $98.75: 1.25$ & 99.37:0.63 & 100 \\
\hline Sabor (0-3) & 0.81 & 0.76 & 1.21 & 1.76 & 2.16 & 2.54 & 2.82 \\
\hline Color (0-3) & 1.52 & 1.47 & 1.93 & 1.88 & 2.12 & 2.85 & 2.82 \\
\hline Olor (0-3) & 0.71 & 1.00 & 0.93 & 1.71 & 1.82 & 2.54 & 2.76 \\
\hline Suavidad (0-5) & 3.83 & 3.76 & 4.68 & 4.09 & 4.34 & 4.96 & 4.59 \\
\hline Tersura (1-2) & 1.19 & 1.06 & 1.79 & 1.88 & 1.94 & 2.00 & 2.00 \\
\hline Inflado (0-2) & 1.00 & 1.00 & 2.00 & 2.00 & 2.00 & 2.00 & 2.00 \\
\hline Doblado (0-2) & 1.19 & 1.29 & 1.71 & 1.35 & 1.76 & 1.69 & 1.76 \\
\hline $\begin{array}{l}\text { Calificación } \\
\text { total }\end{array}$ & 10.25 & 10.34 & 14.25 & 14.67 & 16.14 & 18.58 & 18.75 \\
\hline
\end{tabular}

con los resultados obtenidos en el análisis de crecimiento de las ratas (Tabla 6).

\section{Discusión}

Este estudio demuestra que se puede mejorar la calidad de la tortilla de maíz adicionándola con proteína de sardina, sin modificar sus características físicas y sensoriales. Las tortillas mejoradas potencialmente optimizarían el crecimiento de los niños en poblaciones donde la tortilla de maíz constituye la principal fuente de energía y proteínas y el crecimiento de los niños es deficiente.

Los resultados son comparables a los de otros estudios que han demostrado que la calidad de las tortillas de maíz mejora cuando se adiciona con leguminosas, tanto con harina del grano completo como con extracto de proteínas. Sin embargo, el PER reportado en las dietas adicionadas con leguminosas es de aproximadamente $1.8,{ }^{22,23}$ esto es importante porque, aunque no existe un valor de PER de mejor calidad, se sugiere que por lo menos sea parecido al PER de caseína de 2.5, considerado como la referencia. ${ }^{23}$ El PER obtenido en nuestro estudio para las tortillas con un concentrado de proteína de $3.75 \%$ fue de 2.44, que sugiere que el uso de un concentrado de proteína de sardina es una alternativa mejor que el uso de leguminosas.

Reconocemos que otras pruebas biológicas, como la digestibilidad de las dietas, no fueron realizadas en nuestro estudio, sin embargo, los resultados observados en el crecimiento de las ratas sugieren que la biodisponibilidad de la proteína de las diferentes dietas fue adecuada ya que se observa una asociación directa entre la cantidad de proteína adicionada y el crecimiento de las ratas. Es decir, mientras más concentración
Tabla 6. Pruebas biológicas en las mezclas con mejor calificación física y sensorial comparadas con la tortilla no adicionada y con caseína

\begin{tabular}{lcc}
\hline Mezcla HM:PS & PER experimental & PER ajustado* \\
\hline 96.25:3.75 & 2.17 & 2.44 \\
$97.5: 2.5$ & 1.47 & 1.66 \\
$98.75: 1.25$ & 1.51 & 1.70 \\
$99.37: 0.63$ & 1.35 & 1.52 \\
100:0 (TN) & 1.25 & 1.41 \\
Caseína & 2.22 & 2.50 \\
\hline
\end{tabular}

HM:PS = harina de maíz:proteína de sardina, PER = relación de eficiencia de proteína. ${ }^{*}$ Ajustado a PER de caseína de 2.50

de proteína en las tortillas, mayor el crecimiento de las ratas en una forma de dosis-respuesta (Figura 3).

También reconocemos que este estudio se encuentra en una etapa preliminar antes de proponer la adición de la harina de maíz con proteína de sardina en forma rutinaria. Es indispensable realizar un estudio en un modelo de seres humanos para demostrar que realmente la adición de la proteína de sardina a las tortillas de maíz tiene impacto en el crecimiento de los niños. De la misma manera, será necesario realizar estudios de costo-efectividad para calcular el costo de las tortillas adicionadas en relación con la mejoría en el crecimiento de los niños y lo que esto implica. Por ejemplo, si un mejor crecimiento se refleja en menores tasas de infecciones, hospitalizaciones, tratamientos médicos, etcétera.

Finalmente, consideramos que este resultado es relevante desde el punto de vista de la salud pública porque propone una alternativa para mejorar la dieta $y$, consecuentemente, el estado nutricio de poblaciones con carencias nutricias, particularmente en los lugares donde existen altas tasas de desnutrición y 
el consumo de pescado es común, para mejorar la aceptación de los alimentos.

\section{Agradecimientos}

Agradecemos a la señora Carmen Tavira Mojica, quien facilitó el espacio y equipo para la elaboración de las tortillas

\section{Financiamiento}

El proyecto fue financiado con apoyo FIS/IMSS/ PROT/G12/1155del Fondo de Investigación en Salud del Instituto Mexicano del Seguro Social.

\section{Bibliografía}

1. Dirección General de Epidemiología. Encuesta Nacional de Nutrición 1988. Secretaría de Salud; México, 1988.

2. Rivera-Dommarco J, Shamah-Levy T, Villalpando-Hernández S, González-De-Cossío T, Hernández-Prado B, Sepúlveda J. Encuesta Naciona de Nutrición 1999. Estado nutricio de niños y mujeres en México. México: Instituto Nacional de Salud Pública, 2001.

3. Shamah-Levy T, Villalpando-Hernández S, Rivera-Dommarco JA. Resultados de nutrición de la ENSANUT 2007. México: Instituto Nacional de Salud Pública; 2006.

4. GutiérrezJP, Rivera-DommarcoJ,Shamah-Levy T, Villalpando-HernándezS Franco A, Cuevas-Nasu I, et al. Encuesta Nacional de Salud y Nutrición 2012. Resultados nacionales. México: Instituto Nacional de Salud Pública; 2012.

5. Shamah-Levy T, Cuevas-Nasu I, Rivera-Dommarco J, Hernández-Ávila M. Encuesta Nacional de Salud y Nutrición de Medio Camino 2016. Informe final de resultados. México: Instituto Nacional de Salud Pública; 2016.

6. Roche AF, Sun SS. Human growth: Assessment and interpretation. UK: Cambridge University Press; 2003.

7. Fuller MF. Protein and amino acid requirements. En: Stipanuk $\mathrm{MH}$ Caudill MA, editores. Biochemical and physiological aspects of human nutrition. EE. UU.: Saunders; 2000

8. Millward DJ, Jackson AA. Protein/energy ratios of current diets in developed and developing countries compared with safe protein/energy ratio: implications for recommended protein and amino acid intakes. Public Health Nutr. 2004;7:387-405

9. Chávez Villasana A, Chávez MM. La tortilla de alto valor nutritivo. Evaluación de una harina enriquecida sobre la nutrición y la salud de dos comunidades rurales. México: McGraw-Hill Interamericana; 2004.

10. Bressani R, Elías LG, Scrimshaw NS, Guzmán MA. Nutritive value of Central American corns. VI. Varietal and environmental influence of nitrogen, essential amino acid and fat content of ten varieties. Cereal Chemistry. 1962;39:59-67

11. Organización de las Naciones Unidas para la Agricultura y la Alimentación. El maíz en la nutrición humana. Italia: Organización de las Naciones Unidas para la Agricultura y la Alimentación; 1993.

12. Scrimshaw NS, Bressani R, Behar M, Viteri F. Supplementation of cereal proteins with amino acids. I. Effect of amino acid supplementation of corn masa at high levels of protein intake on the nitrogen retention of young children. J Nutr. 1958;66:485-499.

13. Bressani R, Scrimshaw NS, Behar M, Viteri F. Supplementation of cereal proteins with aminoacids. II. Effect of amino acid supplementation of corn masa at intermediate levels of protein intake on the nitrogen retention of young children. J Nutr 1958;55:501-513.

14. Truswell AS, Brock JF. Effects of amino acid supplements on the nutritive value of maize protein for human adults. Am J Clin Nutr. 1961;9: 715-718.

15. Sauberlich HE, Chang WY, Salmon WD. The comparative nutritive value of corn of high and low protein content for growth in the rat and chick. J Nutr. 1953:51:623-635.

16. Bressani R, Murillo B, Elías LG. Whole soybeans as a means of increasing protein and calories in maize based diets. J Food Sci. 1974;39:577.

17. Méndez-Bueno M, Vela-Gómez GA. Elaboración y evaluación sensorial, química y biológica de tortillas a base de maíz y algunas leguminosas comestibles. [Tesis de licenciatura]. México: Escuela de Ciencias Químicas, Universidad La Salle; 1996.

18. Pérez-Villaseñor J, Del-Valle FR, Salemme MM. Enriquecimiento de las tortillas con proteína de soya por medio de la nixtamalización de mezclas de maíz y frijol de soya. J Food Sci. 1974;39:244-248.

19. Brandsch C, Shukla A, Hirche F, Stangl GI, Eder K. Effect of protein from beef, pork, and turkey meat on plasma and liver lipids of rats compared with casein and soy protein. Nutrition. 2006;22:1162-1170.

20. Sure B. The addition of small amounts of defatted fish flour to whole yellow corn, whole wheat, whole and milled rye, grain sorghum and millet. I. Influence on growth and protein efficiency. II. Nutritive value of the minerals in fish flour. J Nutr. 1957;63:409-416.

21. Mosha TCE, Bennink MR. Protein quality of drum-processed cereal-bean-sardine composite supplementary foods for preschool-age children. J Sci Food Ag. 2004;84:1111-1118.

22. Sagarpa. [Sitio web]. La sardina. [Actualizado 2014 Sep 10] Disponible en: www.sagarpa.gob.mx/saladeprensa/infografias/Paginas/SardinaMexicana.aspx

23. AOAC. [Sitio web]. Official Methods of Analysis of AOAC International $20^{\text {th }}$ edition. Washington, EE. UU.: AOAC; 2016. 